\title{
A Chance Encounter with Copulating Cottonmouths (Agkistrodon piscivorus)
}

George C. Brooks

Department of Animal and Plant Sciences, University of Sheffield, South Yorkshire, S10 2TN, UK (george@brookshome.co.uk)

Photographs by the author.

$\mathrm{C}$ urrent information regarding the timing of mating in wild snakes is almost wholly reliant on the anecdotal evidence of chance encounters (Aldridge and Duvall 2002). Also, implicit correlates of mating, such as male-male combat, often are used to determine mating seasons of viperids, largely because encounters with copulating pairs occur so infrequently (Wharton 1966, Graham et al. 2008, Siegel et al. 2009). Recently, analyses using hormonal and histological correlates of reproductive cycles have been employed in attempts to estimate mating periods (Graham et al. 2008). However, as Graham et al. (2008) noted, these factors can be inconsistent across snake species and, hence, direct evidence from witnessed copulation events remains a valuable foundation from which to draw reliable conclusions about mating seasons. Therefore, additional reports of mating events in snakes, including those species for which information is already available, will enhance our understanding of mating in those species.

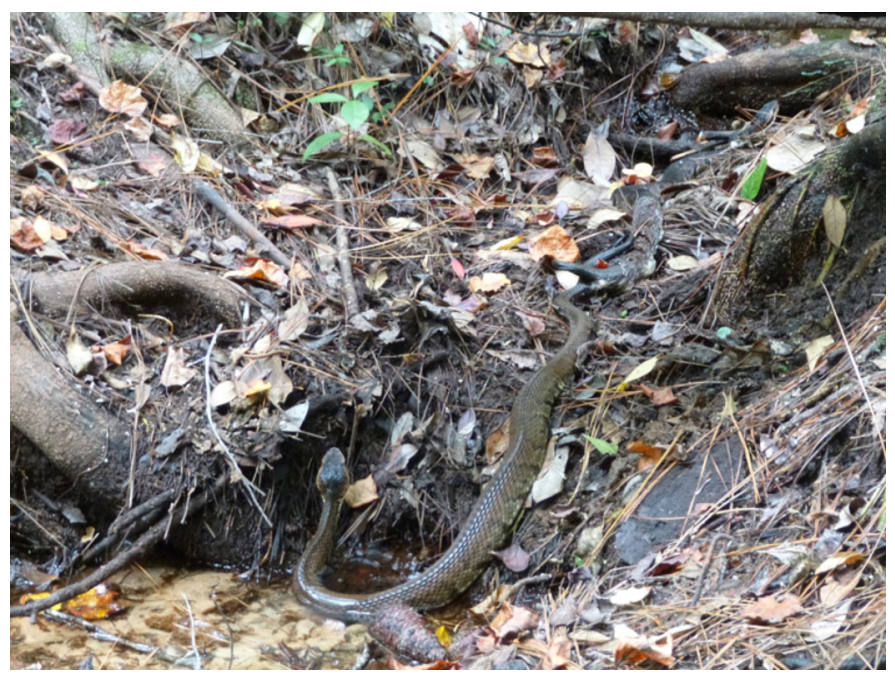

Fig. 1. The original position of two copulating Cottonmouths (Agkistrodon piscivorus) in Covington County, Alabama on 27 August 2012 at approximately $1630 \mathrm{~h}$.
Here I document copulation of Cottonmouths (Agkistrodon piscivorus) observed at approximately $1630 \mathrm{~h}$ on 27 August 2012 in a small inlet of Blue Creek, Covington County, Alabama (31.14449N, 86.67554W). The pair was discovered while conducting surveys of the surrounding seepage habitat.

The snakes were discovered in copula (hemipene intromission was confirmed), facing opposite directions (Fig. 1). They remained motionless in this position for 15 min until, in an attempt to obtain a closer vantage point, I disturbed them. On my approach, the female became agitated and proceeded to drag the male away from my position. At first, she attempted to drag her partner to higher ground, but being significantly smaller, the attempt was unsuccessful. After several minutes, while the male remained passive, the female dragged the male roughly $2 \mathrm{~m}$ through the water and onto the opposite bank (Fig. 2). The female then climbed on top of the male, while both snakes were still partly submerged (Fig. 3).

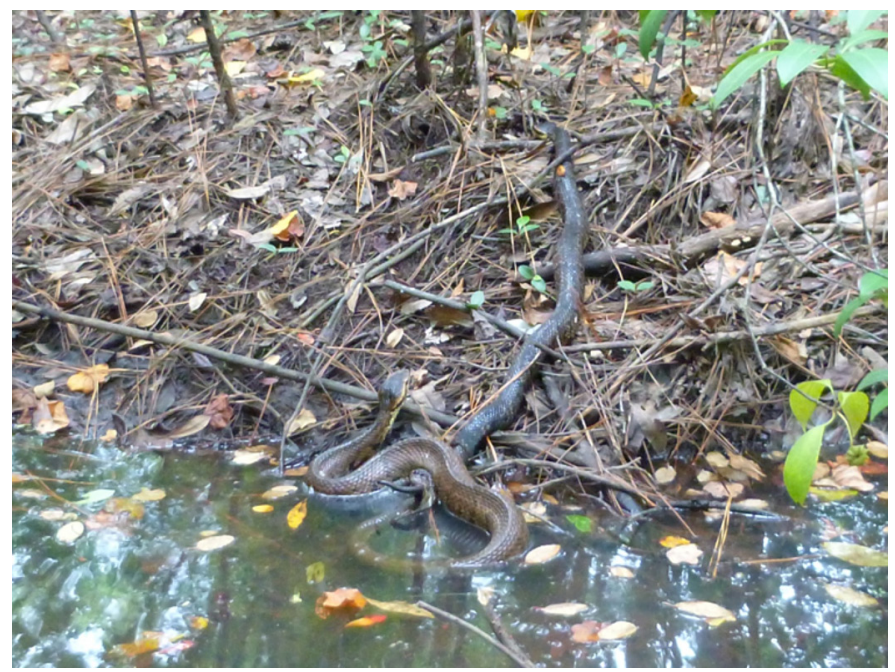

Fig. 2. The female attempts to drag the male out of the water on the opposite bank. 


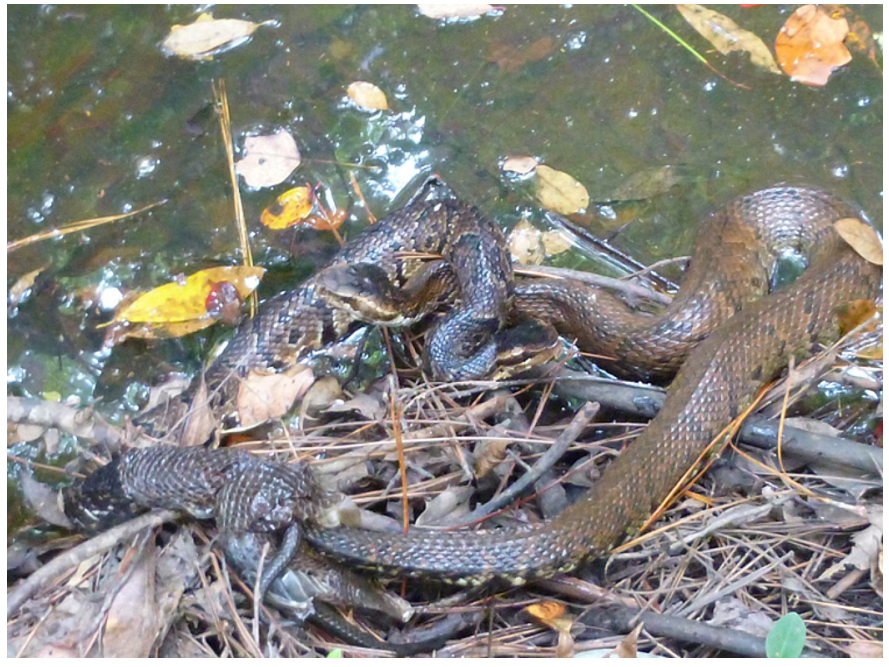

Fig. 3. The female climbs on top of the male while both snakes are still partly submerged.

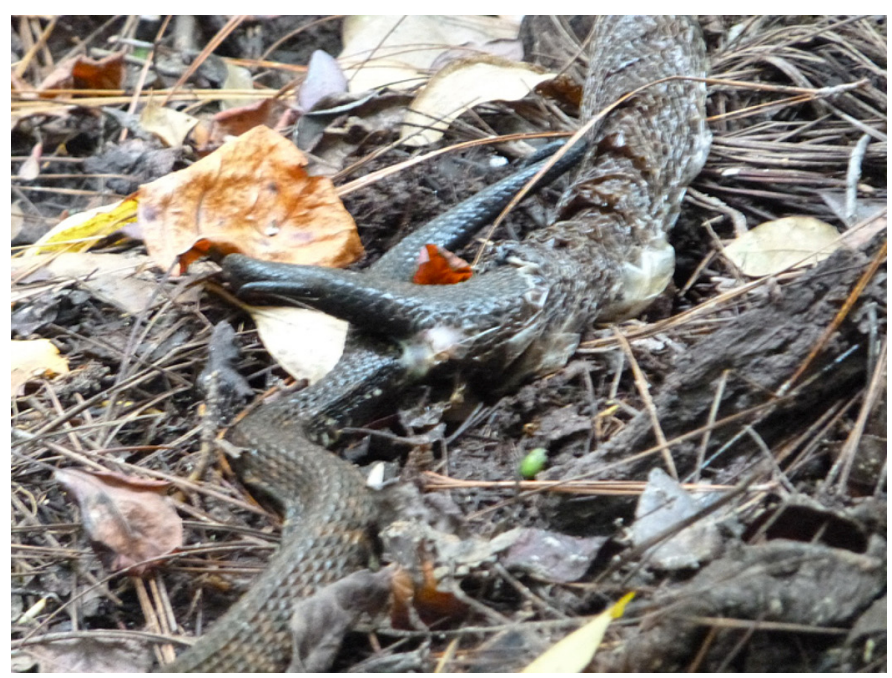

Fig. 4. The male hemipene; the two snakes remained locked for the duration of the observation $(-40 \mathrm{~min})$.

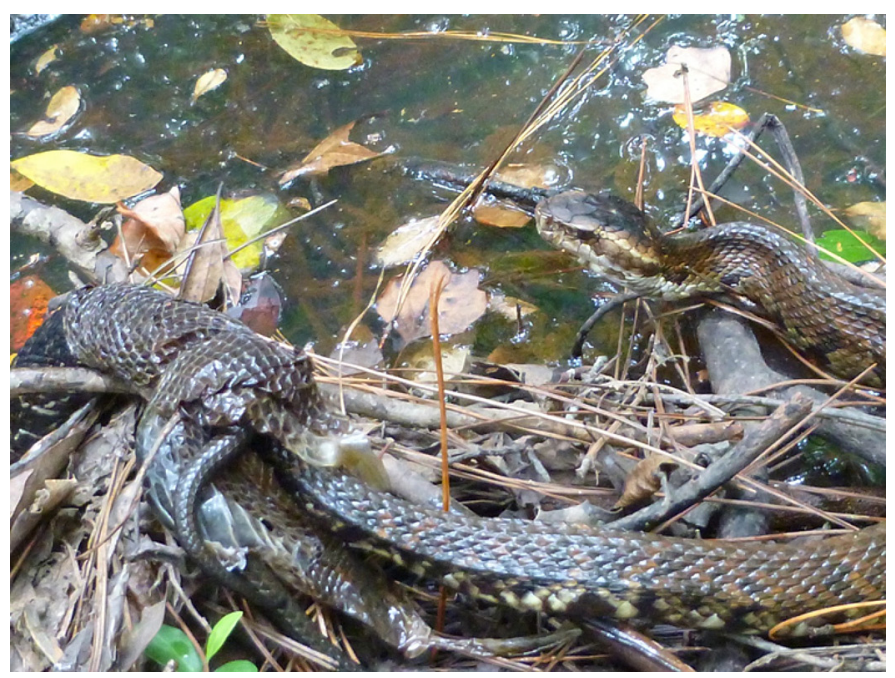

Fig. 5. Remnants of ecdysis are still visible near the tail of the female obscuring the hemipene.
During this entire period, the pair remained locked via the male's hemipene (Fig 4).

The female was identified by its small size in comparison to its partner and close scrutiny of the position of the male's hemipene. Male-biased sexual size-dimorphism has previously been documented in A. piscivorus (Hill and Beaupre 2008). In addition, the female was in the process of ecdysis (Fig 5). The presence of slough on one individual is consistent with previous observations of pitvipers; females shedding prior to mating might indicate a functional link between these two processes (Kubie et al. 1978, Ashton 2003).

Interestingly, Fitch (1975) noted a similar copulation encounter in Diadophis punctatus, in which only the female became agitated when disturbed, resorting to dragging her male partner in an attempt to escape. Fitch (1975) offered no explanation for this behavioral peculiarity, and to my knowledge, no other study has mentioned similar passiveness in copulating male snakes. Unfortunately, the paucity of information regarding reproductive and behavioral ecology in snakes prevents an assessment of whether these observations represent anything more than coincidence.

Clearly more work is needed to obtain a better understanding of mating behavior in snakes, beginning with a more precise estimate of when mating occurs. Histological and observational evidence provided by Siegel and Sever (2007) suggested that $A$. piscivorus displays biennial breeding, with mating seasons in the spring as well as in late summer/ early autumn. This observation joins several others that have reported mating $A$. piscivorus in late summer/early autumn (summarized in Graham et al. 2008), which corresponds with the peak of testosterone production, as well as spermatogenesis and the enlargement of the renal sex segment (Johnson et al. 1982, Zaidan et al. 2003, Graham et al. 2008).

\section{Acknowledgements}

Funding for this research was provided by IOS-1051367 to T. Langkilde. Special thanks go to Sean Graham for his constructive comments on an earlier draft that greatly improved the manuscript.

\section{Literature Cited}

Aldridge, R.D. and D. Duvall. 2002. The evolution of the mating season in the pitvipers of North America. Herpetological Monographs 16:1-25.

Ashton, K.G. 2003. Movements and mating behavior of adult male Midget Faded Rattlesnakes, Crotalus oreganus concolor, in Wyoming. Copeia 2003:190-194.

Fitch, H.S. 1975. A demographic study of the Ringneck Snake (Diadophis punctatus) in Kansas. University of Kansas Museum of Natural History Miscellaneous Publications 62:1-53.

Graham, S.P., R.L. Earley, S.K. Hoss, G.W. Schuett, and M.S. Grober. 2008. The reproductive biology of male Cottonmouths (Agkistrodon piscivorus): Do plasma steroid hormones predict the mating season? General and Comparative Endocrinology 159:226-235.

Hill, J. and S. Beaupre. 2008. Body size, growth, and reproduction in a population of Western Cottonmouths (Agkistrodon piscivorus leucostoma) in the Ozark Mountains of northwest Arkansas. Copeia 2008:105-114.

Johnson, L.F., J.S. Jacob, and P. Torrance. 1982. Annual testicular and androgenic cycles of the Cottonmouth (Agkistrodon piscivorus) in Alabama. Herpetologica $38: 16-25$. 
Kubie, J.L., J. Cohen, and M. Halpern. 1978. Shedding enhances the sexual attractiveness of oestradiol treated garter snakes and their untreated penmates. Animal Behaviour 26:562-570.

Schuett, G.W. 1992. Is long-term sperm storage an important component of the reproductive biology of temperate pitvipers?, pp. 169-184. In: J.A. Campbell and E.D. Brodie (eds.), Biology of the Pitvipers. Selva, Tyler, Texas.

Siegel, D.S. and D.M. Sever. 2007. Sperm aggregations in female Agkistrodon piscivorus (Reptilia: Squamata): A histological and ultrastructural investigation. Journal of Morphology 269:189-206.
Siegel, D.S., D.M. Sever, J.L. Rheubert, and K.M. Gribbins. 2009. Reproductive biology of Agkistrodon piscivorus Lacépède (Squamata, Serpentes, Viperidae, Crotalinae). Herpetological Monographs 23:74-107.

Wharton, C.H. 1966. Reproduction and growth in the Cottonmouth, Agkistrodon piscivorus Lacépède, of Cedar Keys, Florida. Copeia 1966:149-161.

Zaidan, F., III, D.L. Kreider, and S.J. Beaupre. 2003. Testosterone cycles and reproductive energetics: Implications for northern range limits of the Cottonmouth (Agkistrodon piscivorus leucostoma). Copeia 2003:231-240. 